\title{
Nickel Antimony Sulphide Thin Films for Solar Cell Application: Study of Optical Constants
}

\author{
Saima Mushtaq ${ }^{1}$, Bushra Ismail' ${ }^{2}$, Muhammad Raheel ${ }^{1}$, Aurang Zeb ${ }^{1,3}$ \\ ${ }^{1}$ Department of Applied Physics, Federal Urdu University of Arts, Science and Technology, Islamabad, Pakistan \\ ${ }^{2}$ Department of Chemistry, COMSATS Institute of Information Technology, Abbottabad, Pakistan \\ ${ }^{3}$ Department of General Studies, Jubail University College, Jubail Industrial City, KSA \\ Email: *saima.fuuast88@yahoo.com
}

Received 4 December 2015; accepted 31 January 2016; published 3 February 2016

Copyright (C) 2016 by authors and Scientific Research Publishing Inc.

This work is licensed under the Creative Commons Attribution International License (CC BY).

http://creativecommons.org/licenses/by/4.0/

c) (i) Open Access

\begin{abstract}
Chemical bath deposition technique has been used to deposit Ni-doped $\mathrm{Sb}_{2} \mathrm{~S}_{3}$ thin films onto glass substrate. Doping was carried out by adding 1, 3 and 5 wt\% of $\mathrm{Ni}$. Bath temperature was kept as $10^{\circ} \mathrm{C}$ and films were annealed at $250^{\circ} \mathrm{C}$ under vacuum. Polycrystalline nature of films with an orthorhombic phase was analyzed by X-ray diffraction technique. Scanning electron microscopy was used for morphological study which shows that grains are spherical. Optical measurements using transmittance data indicated that films have a direct band gap of $1.00-2.60 \mathrm{eV}$ with an absorption coefficient of $\sim 10^{4} \mathrm{~cm}^{-1}$ in visible range. The average value of electrical conductivity was calculated as 1.66, 1.11 and $1.06(\Omega \cdot \mathrm{cm})^{-1}$ for as-deposited films and $1.90,2.08$ and $1.15(\Omega \cdot \mathrm{cm})^{-1}$ for annealed films while refractive indices were found as $2.18-3.38$ and $1.91-3.74$ respectively. The obtained films can be used for solar cell applications due to their good absorbing properties like higher absorption coefficient and refractive index values.
\end{abstract}

\section{Keywords}

Ni Doped, Optical Constants, $\mathrm{Sb}_{2} \mathrm{~S}_{3}$ Thin Films, Chalcogenides, Solar Cells

\section{Introduction}

Thin films of chalcogenide family (sulphides, selenides, tellurides) are gaining much attention these days due to their wide applications in optoelectronic devices [1]. One of the members of chalcogenide family, antimony

*Corresponding author. 
sulphide $\left(\mathrm{Sb}_{2} \mathrm{~S}_{3}\right)$ is under intense consideration for its use in thin film solar cells [2]. Some of the properties of $\mathrm{Sb}_{2} \mathrm{~S}_{3}$ which signify its large scale applicability in optoelectronics are their high refractive index, absorption coefficient of the order of $10^{5} \mathrm{~cm}^{-1}$, band gap of $1.7 \mathrm{eV}$ and well-defined quantum size effects [3]. Apart from all the above mentioned properties, $\mathrm{Sb}_{2} \mathrm{~S}_{3}$ has problem of high resistivity and low optical transmission, which hinder its applications at large scale [4]. Based on the recent literature survey on the current research trends in the field of design and development of $\mathrm{Sb}_{2} \mathrm{~S}_{3}$ thin films, a two-way approach has been used so far for the alteration of properties. One is the use of various deposition techniques and the other is the modification of properties of $\mathrm{Sb}_{2} \mathrm{~S}_{3}$ by the addition of different dopants. Various techniques are used to deposit amorphous and crystalline $\mathrm{Sb}_{2} \mathrm{~S}_{3}$ thin films such as chemical bath deposition [5], electro-deposition [6], spray pyrolysis [7], vacuum thermal evaporation [8] and dip and dry method [9]. Similarly, different dopants like carbon, tin, lead, bismuth, copper and silver are used to improve the structural, optical and electrical properties of material [10] [11]. Annealing of the films after deposition changes their optical properties due to change in their structure [11].

Both the already mentioned approaches alter the structural and the morphological properties which in turn affect the optical transmission and reflectance of thin films based on their thickness variations. Going through the detailed literature survey on the deposition and properties of thin films, the approach of studies up till now is mostly focused on the phase evolution, grain size and structure and their effects on the transmission properties and band gap values. Although the thorough studies of the optical constants like refractive index, absorption coefficient, extinction coefficient and electrical properties like dielectric constant and electrical conductivity are important for the use of material as an absorbing material in solar cells. Very few reports are found on the studies of optical constants on the bare $\mathrm{Sb}_{2} \mathrm{~S}_{3}$ and their doped derivatives.

The objective of this research is to study the effect of $\mathrm{Ni}$ doping on $\mathrm{Sb}_{2} \mathrm{~S}_{3}$ thin films grown by chemical bath deposition (CBD) technique at substrate temperature of $10^{\circ} \mathrm{C}$. The important characteristic of it is that large area films can be deposited regardless of shape and morphology of the substrate without any sophisticated instrumentation.

\section{Experimental Details}

Nickel antimony sulphide thin films were prepared by chemical bath deposition technique onto glass substrate. The solution was prepared using $650 \mathrm{mg}$ of $\mathrm{SbCl}_{3}$ (Merck, 99\%) dissolved in $10 \mathrm{ml}$ of Acetone and $\mathrm{CH}_{3} \mathrm{COCH}_{3}$ (Merck, 99\%) with $25 \mathrm{ml}$ of $1 \mathrm{M} \mathrm{Na}_{2} \mathrm{~S}_{2} \mathrm{O}_{3}$ (Aldrich, 99\%) dissolved in $65 \mathrm{ml}$ of distilled water. The solution was prepared in $100 \mathrm{ml}$ beaker with 1,3 and $5 \%$ of $\mathrm{NiCl}_{2}$. Orange-yellow solution turned dark orange when kept for 15 to 20 minutes. The glass substrates were cleaned using ethyl alcohol, chromic acid and distilled water. The substrates were kept vertically in solution beaker. The deposition was made at a substrate temperature of $10^{\circ} \mathrm{C}$ for 2 hours. The films were annealed for 2 hours at $250^{\circ} \mathrm{C}$ under low vacuum condition to improve their crystallinity.

Crystal structure of films was obtained by X-ray diffraction technique using PANalytical XPert Pro (Holland). $\mathrm{CuK} \alpha$ radiation with a wavelength of $1.54 \AA$ was used. Scanning electron microscopy (JEO1, JSM-5910) was used for surface morphology of annealed Ni-doped films. Optical transmittance spectra were measured at room temperature in the wavelength range of 400 - $800 \mathrm{~nm}$ using Perkin Elmer Lambda 25 spectrophotometer.

\section{Results and Discussion}

$\mathrm{X}$-ray diffraction measurements were carried out in the range $2 \theta=20^{\circ}-70^{\circ}$ to analyze the crystal structure and grain size of Ni-doped $\mathrm{Sb}_{2} \mathrm{~S}_{3}$ thin films. The comparison of the patterns is done taking standard pattern of orthorhombic $\mathrm{Sb}_{2} \mathrm{~S}_{3}$ (ICSD code: 001-0538) as a reference material [5], as shown in Figure 1. Grain size (D), lattice parameters $(a, b$ and $c)$, unit cell volume $\left(V_{\text {cell }}\right)$ and X-ray density were determined using the following equations [12]:

$$
\begin{gathered}
D(\mathrm{~nm})=\frac{k \lambda}{\beta \operatorname{Cos} \theta} \\
\frac{1}{d^{2}}=\frac{h^{2}}{a^{2}}+\frac{k^{2}}{b^{2}}+\frac{l^{2}}{c^{2}}
\end{gathered}
$$




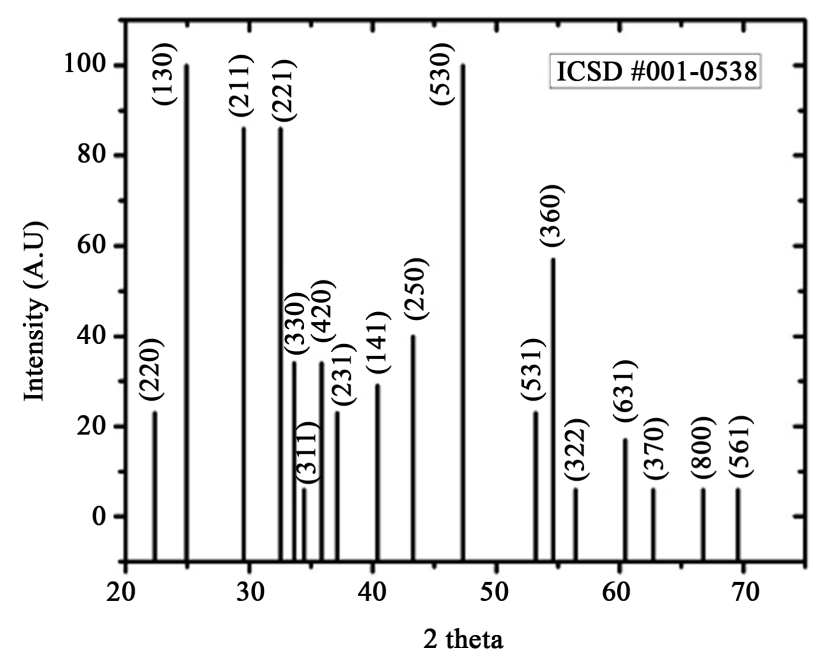

Figure 1. Standard XRD pattern for $\mathrm{Sb}_{2} \mathrm{~S}_{3}$ (ICSD \# 001-0538).

$$
\begin{gathered}
V_{\text {cell }}=a b c \\
\rho_{\text {X-ray }}=\frac{Z M}{V_{\text {cell }} N_{A}}
\end{gathered}
$$

where $\beta$ is full width at half maximum of the peak intensity, $\lambda$ is the wavelength of incident X-ray (1.54 $\AA$ ), $k$ is the shape factor with a value of $0.9, d$ is the d-spacing value between the planes, $h k l$ are miller indices, $\mathrm{Z}$ is number of molecules per formula unit which has a value 4 for the orthorhombic crystal system, $M$ is the molecular weight and $N_{A}$ is the Avogadro's number. X-ray diffraction patterns for Ni-doped $\mathrm{Sb}_{2} \mathrm{~S}_{3}$ thin films with varying concentrations of Ni which are deposited at $10^{\circ} \mathrm{C}$ and annealed at $250^{\circ} \mathrm{C}$ are shown in Figure 2.

A comparison of $2 \theta$ and d-spacing values of the deposited samples with the standard sample is given in Table 1.

The XRD patterns of the deposited samples were compared with standard pattern of $\mathrm{Sb}_{2} \mathrm{~S}_{3}$ (ICSD code: 0010538) with lattice parameters; $a=11.20 \AA, b=11.28 \AA, c=3.83 \AA, V_{\text {cell }}=483.87 \AA^{3}$ and $\rho_{\text {X-ray }}=4.63 \mathrm{~g} / \mathrm{cm}^{3}$. It can be seen that films are polycrystalline with an orthorhombic stibnite phase. The preferential plan for $1 \%$ Ni-doped film was found at $2 \theta=22.31^{\circ}$ corresponding to $h \mathrm{kl}$ plane (220) while for $3 \%$ and $5 \%$ Ni-doped films it was shifted towards $2 \theta=24.92^{\circ}$ with hkl plane (130). The calculated lattice parameters in comparison with un-doped sample [13] are given in Table 2. The lattice parameters for $1 \%$ and $3 \%$ are in good agreement with un-doped $\mathrm{Sb}_{2} \mathrm{~S}_{3}$ thin film sample with the grain size increasing from $21 \mathrm{~nm}$ to $63 \mathrm{~nm}$ while for 5\% Ni-doping, a drastic increase in grain size can be seen, i.e.; grain size was found as $24 \mu \mathrm{m}$. The increase in grain size can be attributed to increase in film thickness with higher Ni concentrations as observed during experimental work and the change in lattice parameters for 5\% doping shows that there may be formation of any other phase of NiSbS.

Scanning electron micrographs for $1 \%, 3 \%$ and $5 \%$ Ni doped $\mathrm{Sb}_{2} \mathrm{~S}_{3}$ thin films are shown in Figure 3 . It can be seen that grains are solid and spherical with well-defined boundaries for all the films. The grains are distributed randomly on the surface for $1 \%$ and $5 \% \mathrm{Ni}$ doping while the inter-grain distance for $3 \% \mathrm{Ni}$ doped film is very small. The growth of particles with increase of Ni concentration can be seen from SEM micrographs. Since the boundaries are clear so we can calculate grain size from SEM micrographs using the mean linear intercept method by the formula:

$$
D=\frac{1.5 L}{N m}
$$

where, $L$ is line length on the micrograph, $N$ is the number of grains crossed by that line, $\mathrm{m}$ is magnification of micrograph and 1.5 is called as the shape factor.

The grain size calculated as 180, 360 and $360 \mu \mathrm{m}$ for 1\%, 3\% and 5\% Ni doped films respectively. The obtained values are greater than the values calculated by XRD due to the reason that XRD gives average information about entire film thickness while SEM extracts the surface analysis in micrometers. 


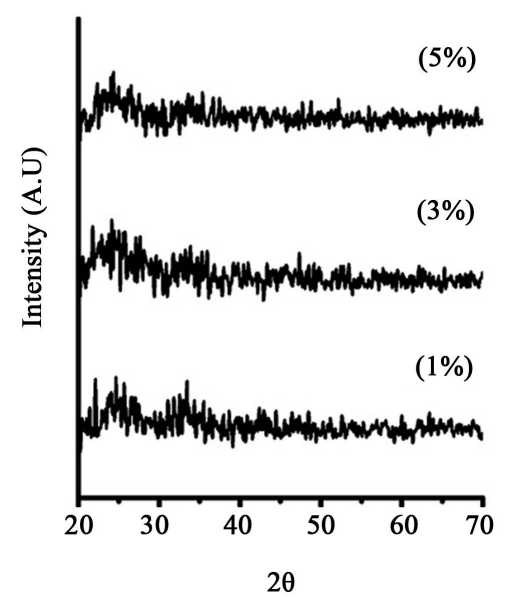

Figure 2. XRD patterns for Ni-doped $\mathrm{Sb}_{2} \mathrm{~S}_{3}$ thin films with varying concentrations of $\mathrm{Ni}$.
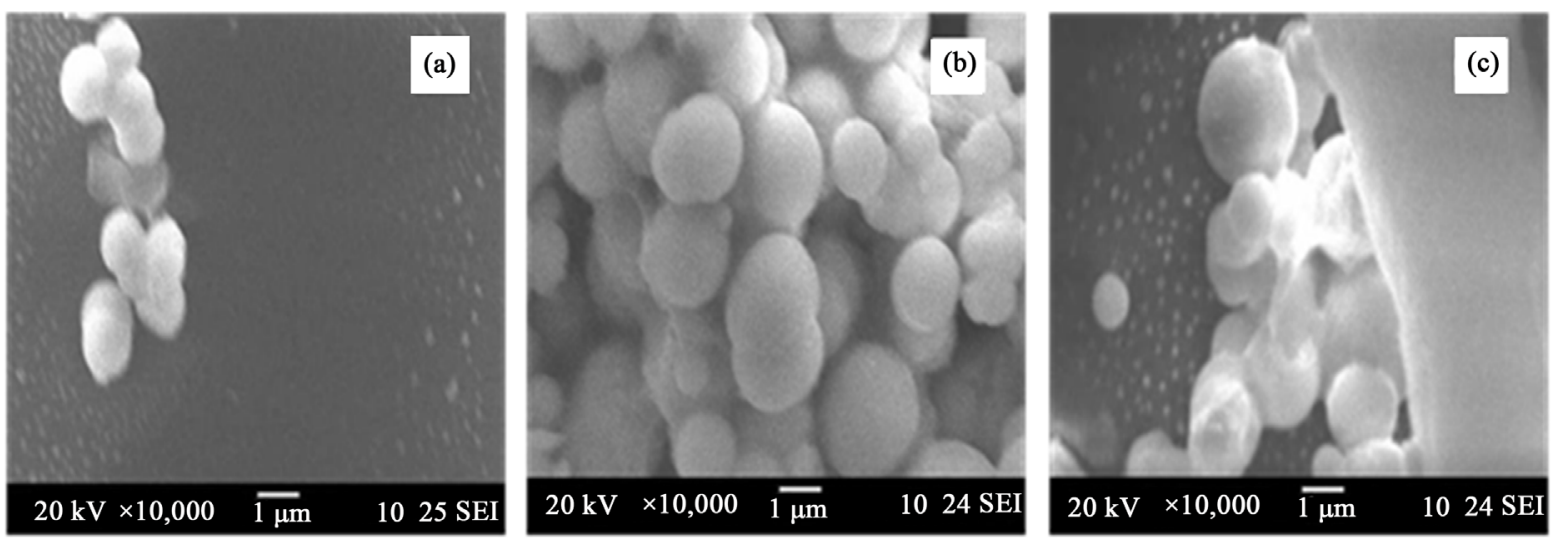

Figure 3. Scanning electron micrographs for Ni-doped $\mathrm{Sb}_{2} \mathrm{~S}_{3}$ thin films with varying concentrations: (a) $1 \%$; (b) $3 \%$ and (c) $5 \%$.

Table 1. Comparison of $2 \theta$ and $d_{h k l}$ values of deposited films with standard pattern of $\mathrm{Sb}_{2} \mathrm{~S}_{3}$.

\begin{tabular}{ccccccccccc}
\hline \multicolumn{2}{c}{ ICSD \# 001-0538 $\left(\mathrm{Sb}_{2} \mathrm{~S}_{3}\right)$} & \multicolumn{2}{c}{$1 \% \mathrm{Ni}$} & \multicolumn{2}{c}{$3 \% \mathrm{Ni}$} & \multicolumn{2}{c}{$5 \% \mathrm{Ni}$} \\
\hline $2 \theta$ & $d_{h k l}$ & $h k l$ & $2 \theta$ & $d_{h k l}$ & $2 \theta$ & $d_{h k l}$ & $2 \theta$ & $d_{h k l}$ \\
\hline 22.37 & 3.970 & 220 & $22.12^{*}$ & 4.017 & 21.78 & 4.079 & 22.82 & 3.897 \\
$24.92^{*}$ & 3.570 & 130 & 24.70 & 3.604 & $24.54^{*}$ & 3.626 & $24.82^{*}$ & 3.587 \\
- & - & - & 25.91 & 3.437 & - & - & - & - \\
33.66 & 2.660 & 330 & 33.90 & 2.667 & - & - & - & - \\
35.89 & 2.500 & 420 & - & - & - & - & 35.41 & 2.534 \\
47.30 & 1.920 & 530 & - & - & 47.26 & 1.923 & - & - \\
53.21 & 1.720 & 531 & - & - & 52.30 & 1.749 & - & - \\
54.58 & 1.680 & 360 & 54.30 & 1.689 & - & - & - & - \\
- & - & - & - & - & 65.26 & 1.429 & - & - \\
69.58 & 1.350 & 561 & - & - & - & - & 69.34 & 1.355
\end{tabular}

*Peak with maximum intensity. 
Table 2. Lattice parameters and grain size of annealed Ni-doped $\mathrm{Sb}_{2} \mathrm{~S}_{3}$ thin films.

\begin{tabular}{ccccccc}
\hline$\% \mathrm{Ni}$ & $a(\AA)$ & $b(\AA)$ & $c(\AA)$ & $V_{\text {cell }}\left(\AA^{3}\right)$ & $\rho_{\text {X-ray }}\left(\mathrm{g} / \mathrm{cm}^{3}\right)$ & $\mathrm{D}(\mathrm{nm})$ \\
\hline$\%$ & 11.47 & 11.22 & 3.81 & 490 & 4.60 & 21 \\
$1 \%$ & 11.21 & 11.42 & 3.98 & 509 & 4.43 & 45 \\
$3 \%$ & 11.40 & 11.60 & 3.79 & 501 & 4.50 & 63 \\
$5 \%$ & 11.50 & 10.50 & 5.40 & 652 & 3.46 & 2413 \\
$\mathrm{Sb}_{2} \mathrm{~S}_{3}{ }^{*}$ & 11.20 & 11.28 & 3.83 & 483 & 4.63 & - \\
\hline
\end{tabular}

*Standard values.

UV/vis spectra of both the as-deposited as well as annealed were taken for the determination of optical constants like refractive index, absorption coefficient, extinction coefficient and electrical properties like dielectric constant and electrical conductivity. The optical absorbance spectra for as-deposited Ni-doped $\mathrm{Sb}_{2} \mathrm{~S}_{3}$ thin films are shown in Figure 4.

The absorbance was calculated in wavelength range of $400-800 \mathrm{~nm}$. It can be seen that the high absorbance region for $1 \% \mathrm{Ni}$-doped films can be found in the range 500 - $700 \mathrm{~nm}$ while for $3 \% \mathrm{Ni}$-doped films maximum value of absorbance can be seen at wavelength of $600 \mathrm{~nm}$. The decreasing values for absorbance can be observed in the wavelength range 450 - $600 \mathrm{~nm}$ for $5 \% \mathrm{Ni}$ doping. Absorbance spectra of the annealed Ni doped thin films were also taken for comparison. These spectra are given in Figure 5.

The absorption coefficient, $\alpha$ can be calculated by transmittance data using following relation

$$
\propto=\frac{1}{d} \ln \frac{(1-R)^{2}}{T}
$$

where $d$ is thickness of film and $R$ is the reflectance. The average value of $\alpha$ was found in the range of $10^{4} \mathrm{~cm}^{-1}$ in visible region for all of the as-deposited as well as annealed Ni-doped thin films (Table 3). The high absorption value $\sim 10^{4} \mathrm{~cm}^{-1}$ has a significant effect on solar conversion efficiency. Gracia et al. have suggested that scattering loses could be the reason for increase in absorbance due to overgrowth of particles on the surface of film [14]. The growth of particles can be seen from SEM images. The increase in grain size also supports the high absorption coefficient value.

The optical band gap of Ni-doped $\mathrm{Sb}_{2} \mathrm{~S}_{3}$ thin films can be determined using Tauce's relation.

$$
(\propto h v)^{1 / n}=A(h v-E g)
$$

where $A$ is constant which depends on transition probability, $E g$ is band gap energy between bottom of conduction band and top of valence band, $n$ is an index parameter with the values 2 and $1 / 2$ for indirect and direct band gap respectively. The band gap values can be obtained by plotting graph between $(\propto h v)^{1 / n}$ and $h v$ as shown in Figure 6 and Figure 7 both for as-deposited and annealed samples. The best linear fit were obtained for $n=$ $1 / 2$ which shows that the dominant transition is direct transition here. The extrapolation of linear portion towards $h v$ gives the value for band gap shown in Table 3 . There could be different reasons for band gap variation like morphology of films, deposition parameters and environment and grain boundaries, etc.

The extinction coefficient $k$ was found using following relation:

$$
k=\frac{\propto \lambda}{4 \pi}
$$

The variation of extinction coefficient values can be depicted from Table 3. It can be seen that the values ranges from $0.10-0.27$ and $0.04-0.24$ for as-deposited and annealed films, respectively. The low value of extinction coefficient for both as-deposited and annealed thin films shows the smoothness and homogeneity of deposited films. The refractive indices for Ni-doped $\mathrm{Sb}_{2} \mathrm{~S}_{3}$ thin films were calculated using the following relation.

$$
n=\frac{1+R}{1-R}+\sqrt{\frac{4 R}{(1+R)^{2}}-k^{2}}
$$




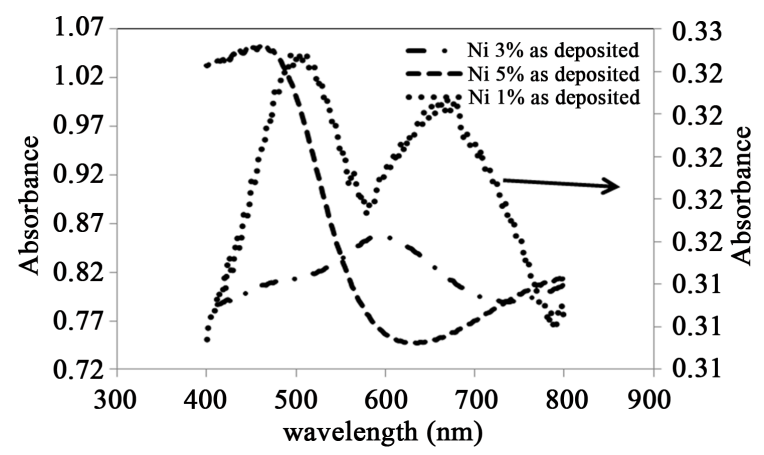

Figure 4. Absorbance spectra of as deposited $\mathrm{Sb}_{2} \mathrm{~S}_{3}$ films with varying Ni concentrations.

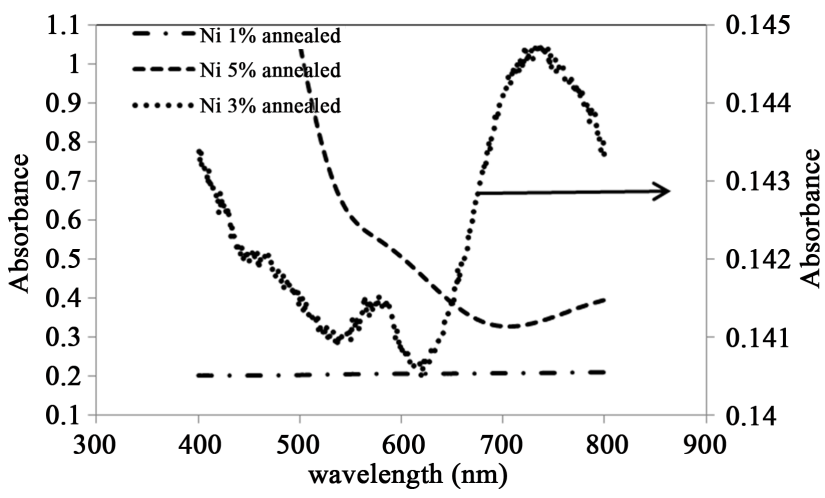

Figure 5. Absorbance spectra of annealed $\mathrm{Sb}_{2} \mathrm{~S}_{3}$ films with varying Ni concentrations.

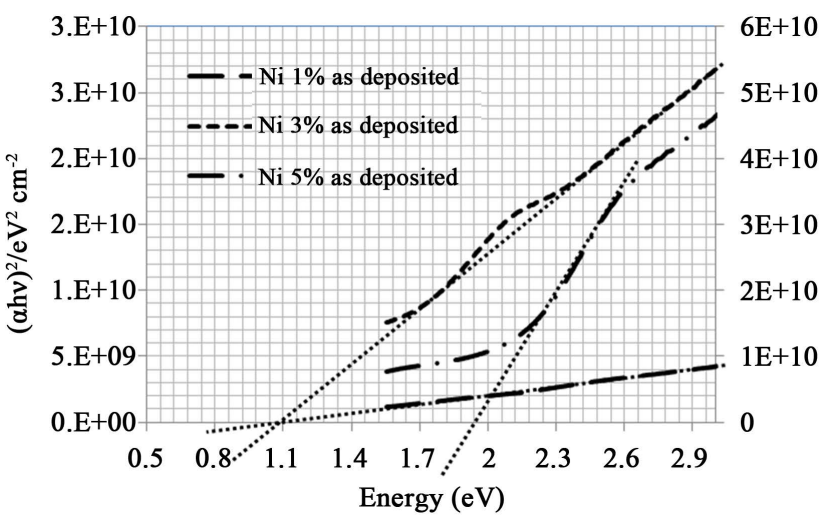

Figure 6. Band gap values obtained for the as deposited samples.

Table 3. Optical parameters for as-deposited and annealed Ni-doped $\mathrm{Sb}_{2} \mathrm{~S}_{3}$ thin films.

\begin{tabular}{|c|c|c|c|c|c|c|c|c|}
\hline \multicolumn{9}{|c|}{ As-deposited } \\
\hline Parameters & $N$ & $k$ & $\varepsilon$ & $\alpha\left(\mathrm{cm}^{-1}\right) \times 10^{4}$ & $\mathrm{Eg}(\mathrm{eV})$ & $\sigma \mathrm{e}(\Omega \cdot \mathrm{cm})^{-1}$ & $\sigma o\left(\mathrm{~s}^{-1}\right) \times 10^{14}$ & $\sigma \mathrm{t}(\mathrm{W} / \mathrm{K} \cdot \mathrm{m}) \times 10^{-8}$ \\
\hline $1 \%$ & 2.18 & 0.10 & 05.21 & 2.21 & 1.00 & 1.66 & 1.15 & 12.14 \\
\hline $3 \%$ & 3.26 & 0.26 & 12.36 & 5.65 & 1.10 & 1.11 & 4.40 & 08.11 \\
\hline $5 \%$ & 3.38 & 0.27 & 13.34 & 5.96 & 1.90 & 1.06 & 4.87 & 07.77 \\
\hline \multicolumn{9}{|c|}{ Annealed } \\
\hline $1 \%$ & 1.91 & 0.06 & 03.91 & 1.43 & 1.00 & 1.90 & 0.65 & 13.87 \\
\hline $3 \%$ & 1.73 & 0.04 & 03.18 & 1.00 & 1.50 & 2.08 & 0.41 & 15.25 \\
\hline $5 \%$ & 3.74 & 0.24 & 22.90 & 5.84 & 2.60 & 1.15 & 8.13 & 08.41 \\
\hline
\end{tabular}




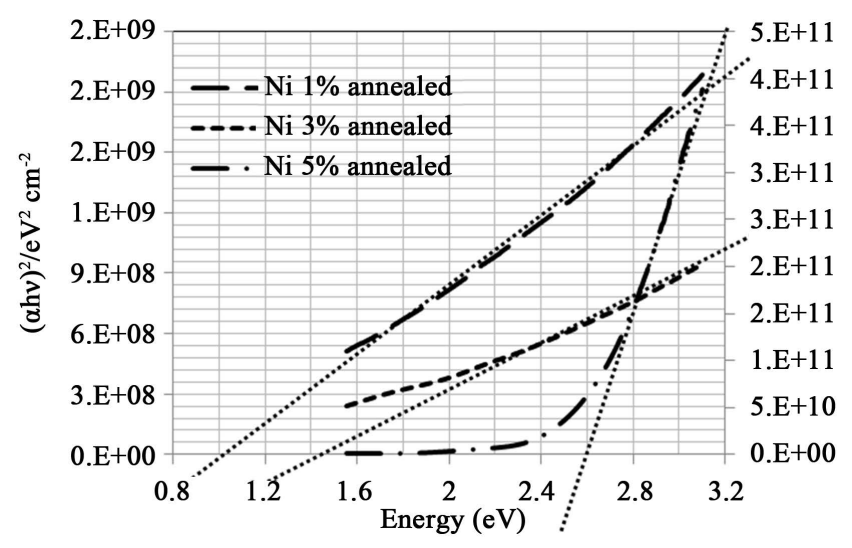

Figure 7. Band gap values obtained for the annealed samples.

The different values of refractive index were calculated in the wavelength range $400-800 \mathrm{~nm}$. The average values are given in Table 3. The high refractive index values can be attributed to increase in crystal quality and grain size. The dielectric constant values were calculated using the relation

$$
\varepsilon=(n-i k)^{2}
$$

The maximum value of dielectric constant was found for 5\% Ni-doped $\mathrm{Sb}_{2} \mathrm{~S}_{3}$ thin films as 13.34 and 22.90 for as-deposited and annealed films, respectively; which show that doping has remarkable effect at higher concentration. The response of optical conductivity $\sigma_{o}$ was seen using the relation.

$$
\sigma_{o}\left(s^{-1}\right)=\frac{\alpha n c}{4 \pi}
$$

Both the as-deposited and annealed Ni-doped $\mathrm{Sb}_{2} \mathrm{~S}_{3}$ thin films have high optical conductivity response $\sim 10^{14}$ $\mathrm{s}^{-1}$ in wavelength range $400-800 \mathrm{~nm}$. The average value for each sample is given in Table 3. Electrical conductivity values were measured using

$$
\sigma_{e}(\Omega \cdot \mathrm{cm})^{-1}=\frac{2 \pi}{\lambda n c}
$$

It can be observed from Table 3 that all the samples have values of the electrical conductivity in the range for semi-conductors, which is $10^{-12}-10^{2}(\Omega \cdot \mathrm{cm})^{-1}[15]$. Thermal conductivity measurements were made using the relation [15]:

$$
\sigma_{T}(\mathrm{~W} / \mathrm{m} \cdot \mathrm{K})=L T \sigma_{e}
$$

where $L$ is Lorentz number with a value of $2.45 \times 10^{-8} \mathrm{~W} \cdot \Omega \cdot \mathrm{K}^{-2}$ and $T$ is temperature. The values for optical constants are given in Table 3.

\section{Conclusion}

Ni-doped $\mathrm{Sb}_{2} \mathrm{~S}_{3}$ thin films have been deposited using chemical bath deposition technique. Doping was carried out using 1, 3 and $5 \mathrm{wt} \%$ of Ni. Polycrystalline orthorhombic crystal structure of films was analyzed using XRD technique. Scanning electron microscopy showed that grains are solid and spherical. The band gap values were calculated in the range $1.0-2.6 \mathrm{eV}$ with an absorption coefficient value $\sim 10^{4} \mathrm{~cm}^{-1}$. The electrical conductivity values were found in limit of values for semiconductor. High absorbance properties confirm its use for solar cell application.

\section{Acknowledgements}

Authors highly acknowledge Late Dr. Syed Tajammul Hussain who has provided us lab facilities at department of Nano Sciences and Catalysis Division, National Center for Physics (NCP) Islamabad for the completion of experimental work. 


\section{References}

[1] Korozlu, N., Colakoglu, K., Deligoz, E. and Ciftci, Y. (2011) The Structural, Electronic and Optical Properties of $\mathrm{Cd}_{\mathrm{x}} \mathrm{Zn}_{1-\mathrm{x}}$ Se Ternary Alloys. Optics Communications, 284, 1863-1867. http://dx.doi.org/10.1016/j.optcom.2010.11.032

[2] Zhang, H., Hu, C., Ding, Y. and Lin, Y. (2015) Synthesis of $1 \mathrm{D} \mathrm{Sb}_{2} \mathrm{~S}_{3}$ Nanostructures and Its Application in VisibleLight-Driven Photodegradation for MO. Journal of Alloys and Compounds, 625, 90-94. http://dx.doi.org/10.1016/j.jallcom.2014.11.052

[3] Ali, N., Ahmed, R., ul Haq, B., Shaari, A. and Jabeen, M. (2015) $200^{\circ}$ C Annealed Combinatorially Deposited Chalcogenide Based Metallic Thin Films for Photovoltaics. Measurements, 63, 81-86. http://dx.doi.org/10.1016/j.measurement.2014.11.024

[4] Calixto-Rodriguez, M., Castillo, F., Martinez, H., Pena, Y. and Sanchez-Juarez, A. (2010) AC Plasma Induced Modifications in Sb2S3 Thin Films. Journal of Physics: Conference Series, 207, No. 1.

[5] Mushtaq, S., Ismail, B., Zeb, M. A., Kissinger, S. and Zeb, A. (2015) Low-Temperature Synthesis and Characterization of Sn-Doped $\mathrm{Sb}_{2} \mathrm{~S}_{3}$ Thin Films for Solar Cell Applications. Journal of Alloys and Compounds, 632, 723-728. http://dx.doi.org/10.1016/j.jallcom.2015.01.307

[6] Yesugade, N., Lokhande, C. and Bhosale, C. (1995) Structural and Optical Properties of Electro Deposited Bi $\mathrm{S}_{3}$, $\mathrm{Sb}_{2} \mathrm{~S}_{3}$ and $\mathrm{As}_{2} \mathrm{~S}_{3}$ Thin Films. Thin Solid Films, 263, 145-149. http://dx.doi.org/10.1016/0040-6090(95)06577-6

[7] Rajpure, K., Lokhande, C. and Bhosale, C. (1997) A Comparative Study of Concentration Effect of Complexing Agent on the Properties of Spray Deposited $\mathrm{Sb}_{2} \mathrm{~S}_{3}$ Thin Films and Precipitated Powders. Materials Chemistry and Physics, 51, 252-257. http://dx.doi.org/10.1016/S0254-0584(97)80314-8

[8] Abd-El-Rahman, K. and Darwish, A. (2011) Fabrication and Electrical Characterization of p-Sb $\mathrm{S}_{3} / \mathrm{n}$-Si Hetero Junctions for Solar Cells Application. Current Applied Physics, 11, 1265-1268. http://dx.doi.org/10.1016/j.cap.2010.12.006

[9] Nayak, B.B., Acharya, H.N., Chaudhuri, T.K. and Mitra, G.B. (1982) The Dip-Dry Technique for Preparing Photosensitive $\mathrm{Sb}_{2} \mathrm{~S}_{3}$ Films. Thin Solid Films, 92, 309-314. http://dx.doi.org/10.1016/0040-6090(82)90153-5

[10] Aousgi, F. and Kanzari, M. (2011) Study of the Optical properties of Sn-Doped $\mathrm{Sb}_{2} \mathrm{~S}_{3}$ Thin Films. Energy Procedia, 10, 313-322. http://dx.doi.org/10.1016/j.egypro.2011.10.197

[11] Cardenas, E., Arato, A., Perez-Tijerina, E., Roy, T.K.D., Castillo, G.A. and Krishnan, B. (2009) Carbon Doped Sb ${ }_{2} S_{3}$ Thin Films: Structural, Optical and Electrical Properties. Solar Energy Materials and Solar Cells, 93, 33-36. http://dx.doi.org/10.1016/j.solmat.2008.02.026

[12] Maghraoui-Meherzi, H., Nasr, T.B., Kamoun, N. and Dachraoui, M. (2010) Structural, Morphology and Optical Properties of Chemically Deposited $\mathrm{Sb}_{2} \mathrm{~S}_{3}$ Thin Films. Physics B: Condensed Matter, 405, 3101-3105. http://dx.doi.org/10.1016/j.physb.2010.04.020

[13] Ismail, B., Mushtaq, S. and Khan, A. (2014) Enhanced Grain Growth in the Sn Doped $\mathrm{Sb}_{2} \mathrm{~S}_{3}$ Thin Film Absorber Materials for Solar Cell Applications. Chalcogenide Letters, 11, 37-45.

[14] Garcia, V.M., Nair, M.T.S. and Nair, P.K. (1991) Optical Properties of PbS/CuxS and $\mathrm{Bi}_{2} \mathrm{~S}_{3} /$ CuxS Thin Films with Reference to Solar Control and Solar Absorber Applications. Solar Energy Materials, 23, 47-59. http://dx.doi.org/10.1016/0165-1633(91)90152-B

[15] Ilenikhena, P.A. (2008) Optical Characterization and Possible Solar Energy Applications of Improved Solution Grown Cobalt Oxide (CoO) Thin Films at 300K. African Physical Review, 2, 68-76. 